\title{
Pola Arus dan Sebaran Sedimen Dasar di Perairan Jepara
}

\author{
Syafiq Muhammad Aziz ${ }^{1}$, Baskoro Rochaddi ${ }^{1}$, Gentur Handoyo ${ }^{1}$, Muslim ${ }^{1}$, Aris Ismanto ${ }^{1}$, Heriyoso \\ Setyono ${ }^{1}$
}

\author{
${ }^{1}$ Departemen Oseanografi, Fakultas Perikanan dan Ilmu Kelautan, Universitas Diponegoro \\ J1. Prof. H. Sudarto, SH, Tembalang Semarang. 50275 Telp/fax (024)7474698 \\ Email corresponding author: syafiqmuhammada@gmail.com
}

\begin{abstract}
Abstrak
Pantai Kartini merupakan pantai yang terletak di wilayah Kabupaten Jepara, terdapat aktifitas pelayaran yang cukup ramai. Adanya jetty dan aktivitas pengerukan di sekitar perairan Pantai Kartini dapat menyebabkan perubahan pola arus dan sebaran ukuran butir sedimen dasar. Penelitian ini bertujuan untuk mengetahui pola arus dan sebaran sedimen dasar permukaan di perairan Jepara. Metode yang digunakan dalam penelitian ini adalah metode kuantitatif dan penentuan lokasi pengambilan sampel sedimen menggunakan metode purposive sampling. Data yang diperlukan untuk mengetahui pola arus yaitu pasang surut, dan data kedalaman perairan menggunakan instrumen singlebeam echosounder. Sedangkan data yang diperlukan untuk mengetahui persebaran ukuran butir sedimen yaitu sampel sedimen dasar. Pengolahan data menggunakan Microsoft Excel, ArcGIS 10.3, Mike21, WrPlot, worldCurrent1.0, sedangkan sampel sedimen diolah menggunkan metode pengayakan dan pemipetan. Hasil dari penelitian ini menunjukan bahwa ukuran butir sedimen dasar yang ditemukan berupa Pasir, Pasir Lanauan dan Lanau. Perairan Pantai Kartini, Jepara memiliki bilangan Formzahl (F) sebesar 1,10 sehingga tergolong pasang surut tipe campuran condong ke harian ganda. Berdasarkan hasil pengolahan software world current 1.0 arus rata - rata menunjukkan $74,6 \%$ arus pasut (astronomic) dan $25,5 \%$ arus non-pasut (residual). Pola arus perairan Pantai Kartini Jepara pada saat pasang menuju ke Utara dan pada saat surut menuju ke Barat Daya.
\end{abstract}

Kata Kunci: Sedimen Dasar, Arus, Pantai Kartini

\begin{abstract}
Kartini Beach is a beach located in Jepara Regency, there are quite busy shipping activities. The existence of jetties and dredging activities around the waters of Kartini Beach can cause changes in flow patterns and size distribution of basic sediment grains. The purpose of this study is to determine the flow patterns and distribution of surface sediment in the waters of Kartini Beach, Jepara. The method used in this study is the quantitative method and the determination of the location of sediment sampling using the purposive sampling method. Data that needed to determine the pattern of currents namely tides, and water depth data using single beam echosounder. Meanwhile the data needed to study sediment size samples are basic sediment samples, Data processing using Microsoft Excel, ArcGIS 10.3, Mike21, WrPlot, world Current 1.0, meanwhile sediment samples are processed using filtering and pipette methods. The results of this study indicate that the size of the sediment grains found were sand, silt sand and silt. The Fromzahl (F) number is 1,10 so it is classified as a mixed tide prevailing semidiurnal. Based on the results of the processing by using World Current 1.0, as much as $74.6 \%$ of the tidal currents (astronomic) and $25.4 \%$ is non-tidal currents (residual). Flow pattern from kartini beach at high tide to the north and at low tide to the Southwest
\end{abstract}

Keywords: Seabad Sediment, Current, Kartini Beach.

\section{PENDAHULUAN}

Proses sedimentasi di daerah pantai sangat dipengaruhi oleh faktor fisik, baik yang berasal dari darat maupun dari laut, salah satu faktor fisik tersebut adalah arus (Simatupang, 2016). Arus dapat memindahkan sedimen dari satu tempat ke tempat yang lain dikarenakan arus memiliki sirkulasi yang dinamis, pada saat pasang arus bergerak dari laut menuju perairan pantai, dan pada saat surut arus bergerak dari perairan pantai menuju laut (Kurniawan, 2016). 
Pantai Kartini merupakan pantai yang terdapat aktivitas pelayaran, aktifitas pengerukan dan terdapat bangunan pantai di daerah tersebut. Aktifitas pelayaran dan pengerukan dapat menyebabkan perubahan pola arus dan sebaran ukuran butir. Tujuan dari penelitian ini adalah untuk mengetahui pola arus dan sebaran sedimen dasar di perairan Pantai Kartini Jepara

\section{MATERI DAN METODE}

Materi yang digunakan pada penelitian ini meliputi data utama dan data penunjang. Data utama yaitu data sampel sedimen dan arus, sampel sedimen diambil menggunakan sedimen grab dan arus menggunakan alat Acoustik Doppler Current Profiler (ADCP) SonTek Argunaut-XR. Sedangkan, untuk data penunjang berfungsi sebagai pendukung dalam pengolahan data. Data penunjang yaitu peta Rupa Bumi Indonesia (RBI), Batimetri (data Kedalaman) yang didapatkan dari data lapangan dan Badan Informasi Geospasial (BIG) serta Pasang surut stasiun Jepara

Metode yang digunakan adalah berupa metode kuantitatif dikarenakan metode tersebut memenuhi kaidah ilmiah dan memberikan data penelitian berupa statistik atau model (sugiyono, 2009). Metode penentuan titik sampling yaitu metode Purposive Sampling, metode pengambilan sampel dengan pertimbangan mewakili daerah penelitian (sugiyono, 2009).

Penelitian dilaksanakan tanggal 8 - 11 September 2018 pengambilan sampel sedimen dan 7 - 11 Maret 2019 pengambilan data arus di Perairan Pantai Kartini Jepara. Lokasi Penelitian tersebut terletak pada koordinat $110^{\circ} 38^{\prime} 00^{\prime \prime}-110^{\circ} 39^{\prime} 30^{\prime \prime} \mathrm{E}$ dan $6^{\circ} 34^{\prime} 30^{\prime \prime}-6^{\circ} 36^{\prime} 00^{\prime \prime} \mathrm{S}$.

\section{HASIL DAN PEMBAHASAN}

\section{Pasang Surut}

Pengamatan pasang surut dilakukan selama 30 hari pada bulan Maret 2019. Data pasang surut diolah menggunakan metode Admiralty, untuk mendapatkan nilai komponen pasang surut S0, M2, S2, N2, K1, O1, M4, MS4, K2, P1. Nilai komponen tersebut diperoleh nilai MSL (Mean Sea Level) adalah 83,22 cm, HHWL (Highest High water Level) adalah 135,94 cm, LLWL (Lowest Low Water Level) adalah 41,01 cm. Nilai Formzahl 1,10, maka dapat diketahui pasang surut di perairan Pantai Kartini Jepara bertipe campuran condong ganda.

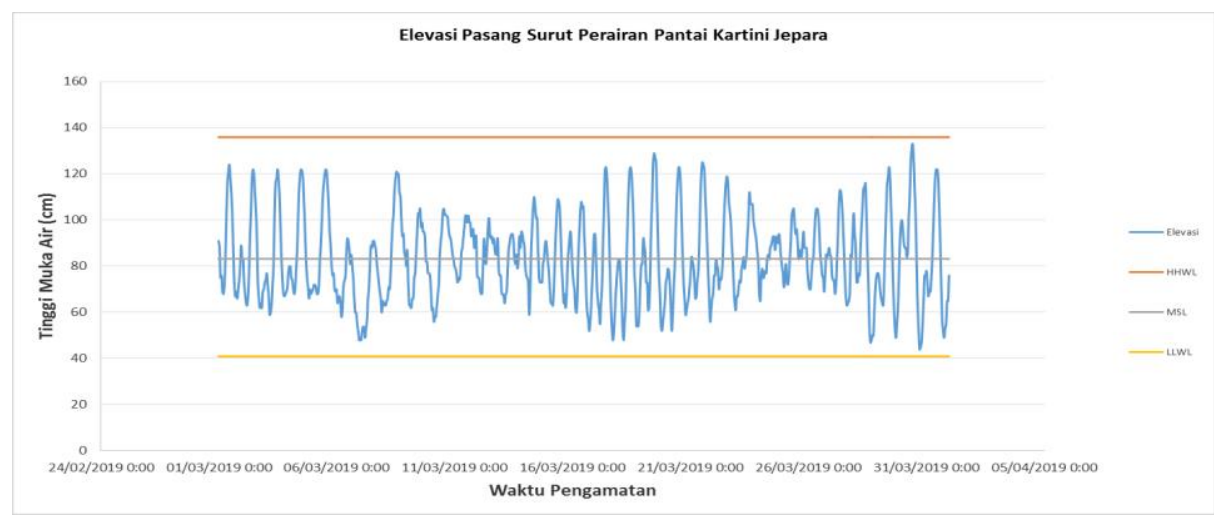

Gambar 1. Grafik Elevasi Pasang Surut

\section{Arus Laut}

Data Kecepatan dan Arah Arus terdiri dari 3 kedalaman yaitu permukaan, tengah dan dasar. Data kecepatan arus rata - rata adalah arus rata - rata yang terjadi pada seluruh kolom air kedalaman pada perairan tersebut.

Berdasarkan hasil dari pengolahan data arus yang tersaji pada Tabel 1. Arus kecepatan maksimal terjadi pada arus permukaan dengan kecepatan maksimal $0,297 \mathrm{~m} / \mathrm{s}$ dan arus minimum pada dasar perairan dengan kecepatan $0,006 \mathrm{~m} / \mathrm{s}$. 
Tabel 1. Kecepatan Arus

\begin{tabular}{cccc}
\hline \multirow{2}{*}{ Kedalaman } & \multicolumn{2}{c}{ Kecepatan } & \multicolumn{2}{l}{ Rata-Rata Kecepatan } \\
& Max $(\mathrm{m} / \mathrm{s})$ & Min $(\mathrm{m} / \mathrm{s})$ & \\
\hline permukaan & 0.297 & 0.025 & 0.117 \\
Tengah & 0.193 & 0.013 & 0.080 \\
Dasar & 0.199 & 0.006 & 0.073 \\
Rata - rata & 0.2 & 0.008 & 0.069 \\
\hline
\end{tabular}

Dari grafik scatterplot untuk memberikan gambaran sebaran arus pada kecepatan tertentu dari dua komponen kecepatan arus yaitu kecepatan arus $\mathrm{U}$ dan $\mathrm{V}$.

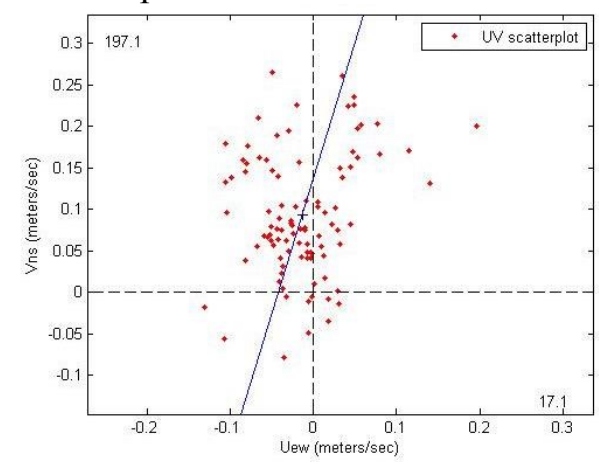

a. Kolom Air Permukaan

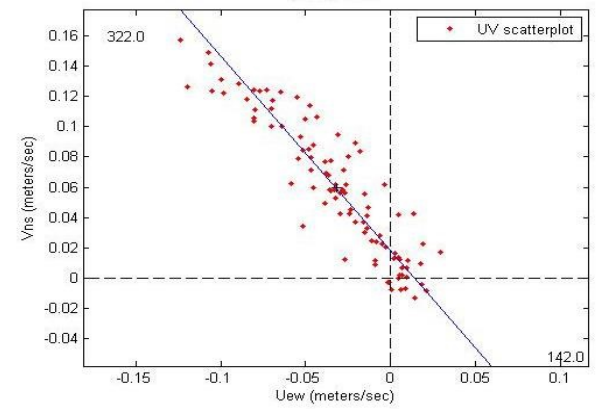

b. KolomPerairan Tengah

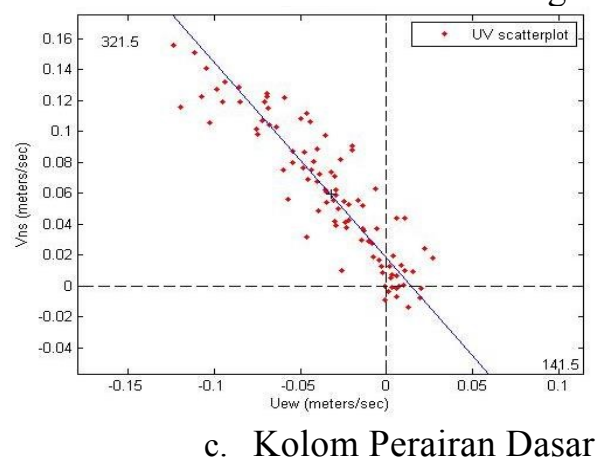

Gambar 2. Scatter Plot

Arus yang terjadi di perairan Pantai Kartini Jepara adalah arus pasang surut. Hal ini didapatkan dari hasil scatterplot yang menunjukkan bahwa arus berbentuk elips. Arus yang berbentuk elips menunjukkan bahwa arus tersebut merupakan arus pasang surut (Leksono, 2013). 
Program World Current 1.03 digunakan untuk membantu analisis arus, apakah dominan arus pasang surut atau arus non pasang surut dengan melihat dari grafik. Gambar 3 menjukkan hasil dari grafik arus pasang surut dengan menggunakan program World Current 1.03 selama 4 hari.

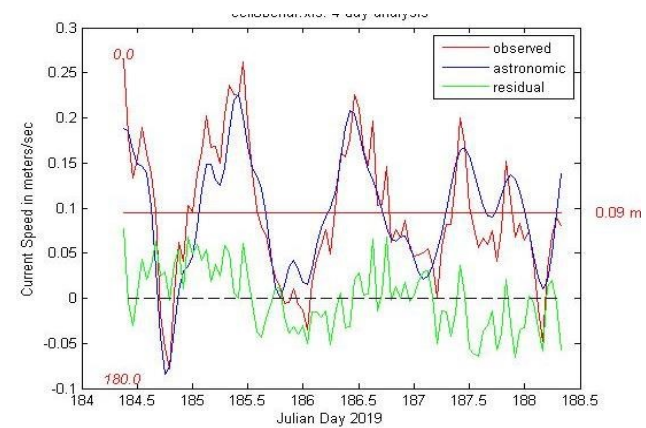

a. Kolom permukaan

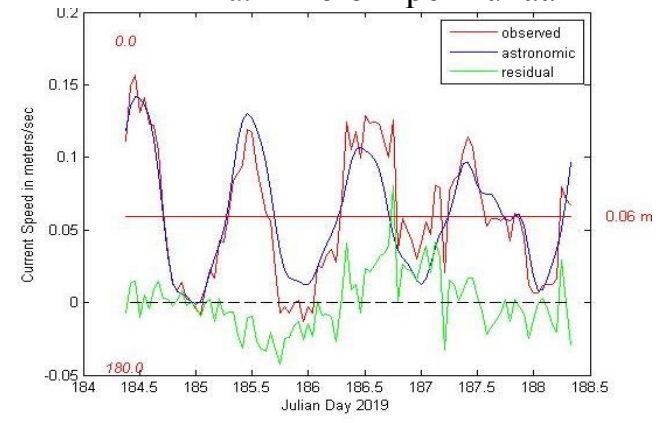

b. Kolom Perairan Tengah

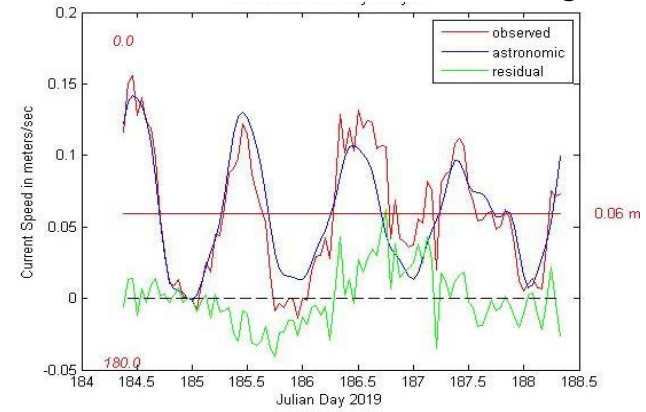

c. Kolom Dasar Perairan

Gambar 3. Grafik Arus Time Series

Pola Arus Perairan

Hasil pemodelan diperoleh simulasi pola pergerakan arus di Perairan Pantai Kartini Jepara. Gambaran pola penyebaran sirkulasi arus disajikan dalam kondisi menuju pasang, pasang, menuju surut dan surut. Hasil model tersaji pada Gambar 4-7. 


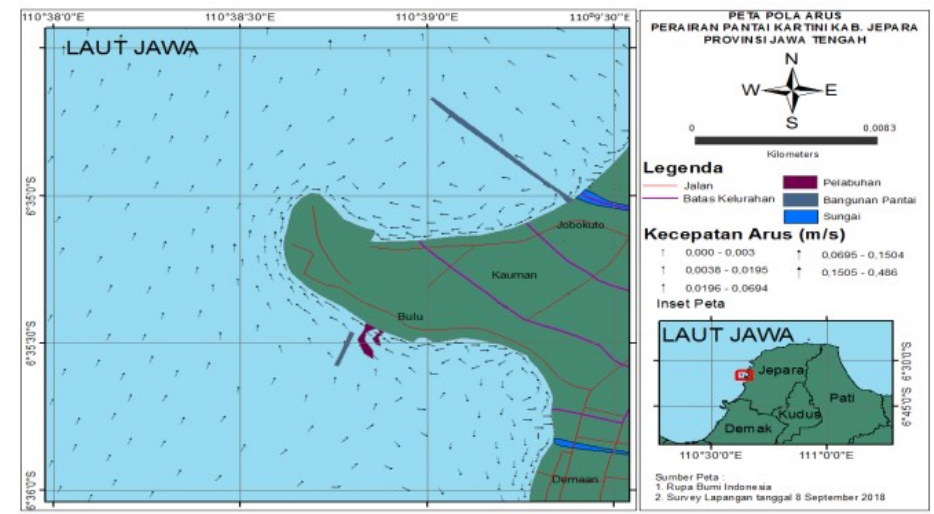

Gambar 4. Pola Arus Saat Menuju Pasang

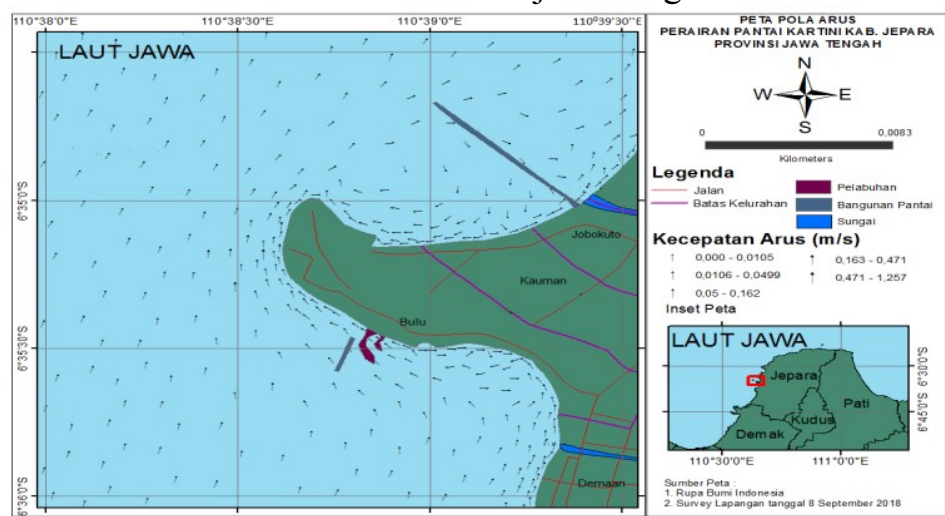

Gambar 5. Pola Arus Saat Pasang

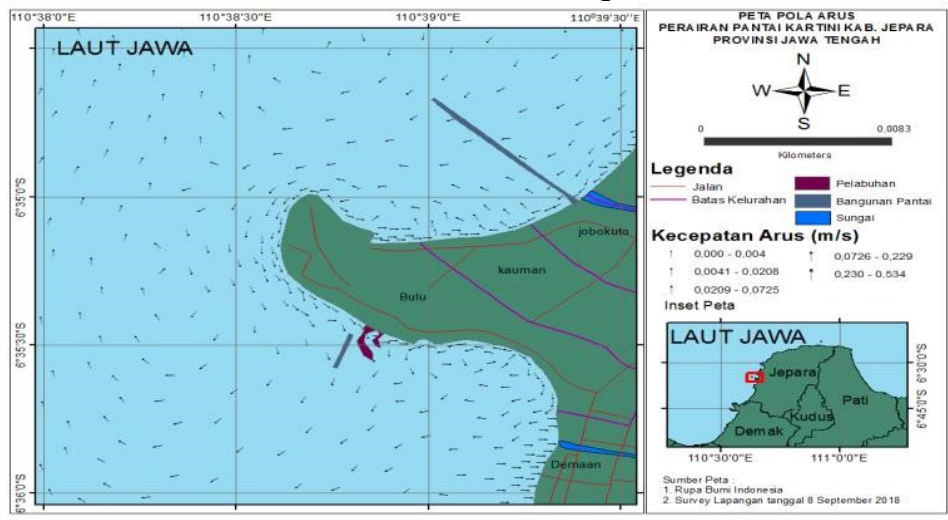

Gambar 6. Pola Arus Saat Menuju Surut

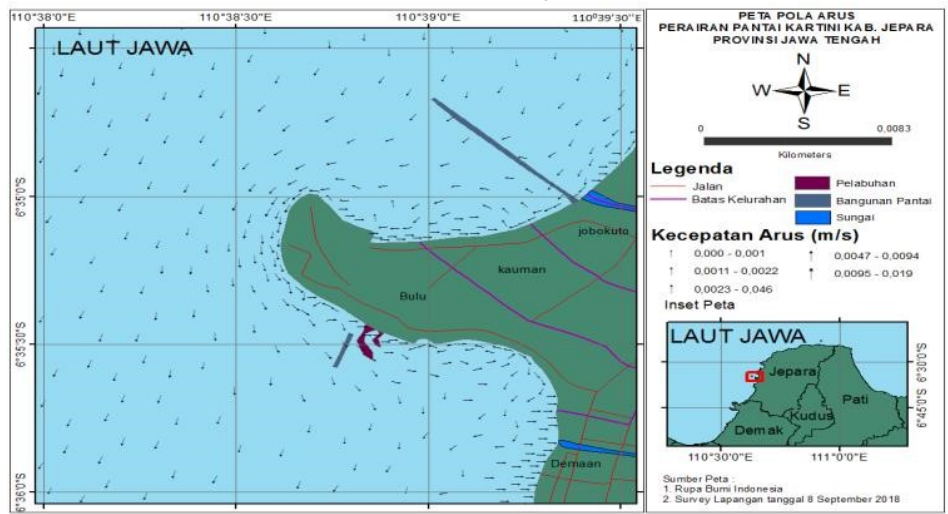

Gambar 7. Pola Arus Saat Surut 
Persebaran Sedimen Dasar

Pengolahan data sedimen dasar menghasilkan ukuran butir pasir, pasir lanauan, dan lanau. Kemudian pada masing - masing stasiun memiliki nilai presentase ukuran butir. Presentase kandungan ukuran butir tersebut dapat dilihat pada Tabel 2. Kemudian hasil dari ukuran butir tersebut ditampilkan pada Gambar 8 .

Tabel 2. Penamaan dan Ukuran Butir Sedimen dari Tiap Stasiun

\begin{tabular}{ccccc}
\hline Stasiun & \multicolumn{3}{c}{ Kandungan (\%) } & Ukuran Butir \\
\hline 1 & Sand & Silt & Clay & \\
2 & 64,32 & 33,23 & 3,45 & Pasir Lanauan \\
3 & 58,18 & 28,93 & 5,01 & Pasir Lanauan \\
4 & 94,63 & 4,0538 & 0,326 & Pasir Lanauan \\
5 & 94,27 & 4.7 & 0 & Pasir \\
6 & 95,45 & 3,15 & 0,35 & Pasir \\
7 & 0,68 & 98,95 & 0,36 & Lanau \\
8 & 96,24 & 2,55 & 0,188 & Pasir \\
9 & 8,57 & 88,14 & 3,081 & Lanau \\
10 & 1,37 & 98,205 & 0,32 & Lanau \\
11 & 88,48 & 5,70 & 1,8 & Pasir \\
12 & 0,44 & 99,17 & 0,38 & Lanau \\
13 & 0,54 & 99,15 & 0,29 & Lanau \\
14 & 19,45 & 79,61 & 0,81 & Lanau \\
15 & 14,83 & 75,43 & 9,63 & Lanau \\
16 & 94,86 & 2,73 & 0,06 & Pasir \\
17 & 19,51 & 79,65 & 0,971 & Lanau \\
18 & 20,16 & 79 & 0,73 & Lanau \\
19 & 1,6 & 97,33 & 1,06 & Lanau \\
\hline
\end{tabular}

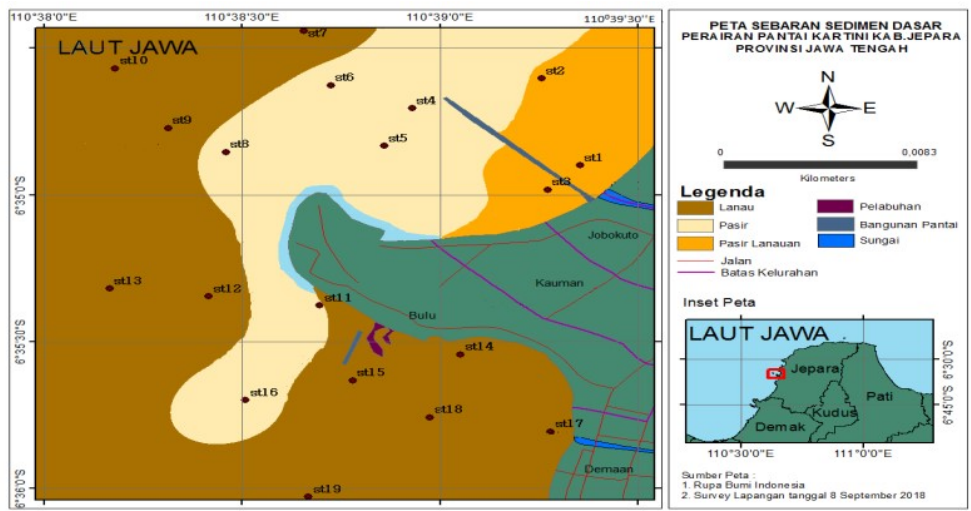

Gambar 8. Sebaran Sedimen Dasar

\section{Pembahasan}

Grafik tersebut dibagi dalam 3 kedalaman. Dari hasil grafik menunjukkan bahwa arus pasang surut (Astronomic) mengikuti arus lapangan (Observed) dibandingkan dengan arus residu (residual). Hal ini menunjukkan bahwa arus yang terjadi di perairan Pantai Kartini Jepara adalah arus pasang surut. Dari hasil pola arus didapatkan bahwa pada saat pasang arus bergerak ke utara dan pada saat surut arus bergerak ke arah barat daya. Pada perairan dekat pantai pola arus cenderung bervariasi dikarenakan pengaruh dari morfologi panta. Menurut Rampengan (2019) pola arus yang tidak merata tersebut dikarenakan gaya gesek pada dasar 
laut. Perubahan pola arus yang mengalami transisi pada saat pola arus menuju surut dan pada saat menuju pasang. Pola arus tersebut bertransisi dari barat daya menuju ke utara maupun sebaliknya, hal ini sesuai dengan pernyataan (Azis, 2006) bahwa arus bergerak secara dinamis.

Sebaran sedimen di daerah pantai kartini jepara mempunyai 3 ukuran butir sedimen yaitu pasir, pasir lanauan, dan lanau. Ukuran butir di lepas pantai didominasi oleh Lanau yang merupakan ukuran butir sedimen berukuran halus, maka arus kecil bisa mentransportkan ukuran tersebut. Sedimen dengan ukuran butir lanau dominan di wilayah yang memiliki kedalaman yang cukup dalam. Hal ini sesuai dengan pernyataan Hutabarat (1985) sebagian besar dasar laut yang dalam ditutupi oleh jenis partikel-partikel yang berukuran kecil yang terdiri dari sedimen halus. Pada stasiun 17 yang dekat dengan muara sungai kali kanal memiliki ukuran butir lanau, ukuran butir tersebut berasal dari hulu menuju ke hilir sungai kali wiso yang mampu mempengaruhi ukuran butir di sekitar wilayah kali kanal. Ukuran butir lanau dapat menyebabkan sedimentasi, hal ini diperkuat dengan pernyataan Astrini (2014) yang mengatakan bahwa tipe substrat pada muara sungai berupa lanau (silt) dan lempung (clay), Substrat tersebut menunjukkan bahwa pada daerah muara sungai mempunyai tingkat sedimentasi yang tinggi

Di daerah pantai didominasi oleh pasir, dikarenakan daerah tersebut merupakan pantai berbentuk tanjung. menurut Ningsih (2002) tanjung merupakan daerah konvergensi sehingga tinggi gelombang menjadi lebih besar dibanding daerah teluk, maka dari itu menyebabkan terjadinya pengendapan ukuran butir pasir pada ujung daratan. Menurut pernyataan Poerbandono dan Djunarsjah (2005) sedimen dapat terangkur secara terus menerus (menggelinding, meluncur, atau melompat - lompat) dengan dasar perairan jika kekuatan arus tersebut besar. Oleh karena itu semakin kuat arus maka semakin banyak dan besar pula ukuran butir yang akan ikut terbawa.

Pada stasiun 1, 2 dan 3 merupakan ukuran butir pasir lanauan, stasiun tersebut dekat dengan muara sungai kali wiso, kali wiso berpotensi terjadi sedimentasi dikarenakan angkutan sedimen yang berasal dari hulu menuju muara sungai kali wiso. ukuran butir pasir lanauan diakrenakan tercampurnya ukuran butir pasir dan ukuran butir lanau dari kali wiso dan adanya peengerukan yang menyebabkan tercampurnya fraksi sedang sampai kasar. Pengerukan itu menyebabkan kondisi perairan di daerah tersebut tidak stabil. Menurut Nugroho dan Abdul (2014) mengatakan kondisi perairan dan arus yang tidak stabil menyebabkan pengendapan fraksi dari sedang sampai kasar.

\section{KESIMPULAN}

Berdasarkan hasil dari penelitian ini adalah terdapat 3 ukuran butir yang terdapat pada perairan Pantai Kartini Jepara diantaranya adalah Pasir, Pasir Lanauan dan Lanau. Pasir terdapat pada daerah pantai, pasir lanauan dan lanau terdapat pada muara sungai dan lepas pantai. Arah dari pola arus di perairan Pantai Kartini Jepara pada saat pasang ke arah utara dan pada saat surut ke arah barat daya.

\section{DAFTAR PUSTAKA}

Astrini, Ananda Dhea Retno, Muh. Yusuf dan Adi Santoso. 2014. Kondisi Perairan Terhadap Struktur Komunitas Mikrozoobenthos Di Muara Sungai Karanganyar dan Tapak, Kecamatan Tugu, Semarang. Journal of Marine Research. Volume 3, Nomor 1, hlm 27-36.

Azis, M Furqon. 2006. Gerak Air Di Laut. LIPI. Volume XXXI, Nomor 4, hlm 9 - 21.

Hutabarat, S dan S.M. Evans. 1985. Pengantar Oceanografi. UI Press, Jakarta.

Leksono, Anindito, Warsito Atmodjo, Lilik Maslukah. 2013. Studi Arus Laut Pada Musim Barat di Perairan Pantai Kota Cirebon. Jurnal Oseanografi Vol 2 No 3 hlm 206 - 213.

Ningsih, N. S. dan Safwan H. 2002. Studi Awal Pemodelan Spektrum Energi Gelombang Laut di Laut Jawa. Dalam: Prosiding Seminar Offshore Tehnology 2002. Institut Teknologi Bandung. Bandung.

Nugroho, Septriono Hari dan Abdul Basit. 2014. Sebaran Sedimen Berdasarkan Analisis Ukuran Butir di Teluk Weda, Maluku Utara. Jakarta: Lembaga Ilmu Pengetahuan Indonesia (LIPI) Ambon. Jurnal Ilmu dan Teknologi Kelautan Tropis., 6(1):229-240.

Poerbandono dan Djunarsjah, E. 2005. Survei Hidrografi. Refika Aditama. Bandung.

Rampengan, R. M. 2009. Pengaruh Pasang Surut pada pergerakan arus permukaan di Teluk Manado. Journal Perikanan Dan Ilmu Kelautan Tropis, V (3), 15 - 19.

Sugiyono. 2009. Metode Penelitian Kuantitatif dan Kualitatif. Bandung: CV.Alfabeta. 